(C) 1982. The Genetical Society of Great Britain

\title{
A MUTATIONAL ANALYSIS OF THE ALCOHOL DEHYDROGENASE SYSTEM IN BARLEY
}

\author{
N. P. HARBERD and K. J. R. EDWARDS \\ Department of Genetics, University of Cambridge, Downing Street, \\ Cambridge CB2 3EH, U.K.
}

Received 14.ix.81

\begin{abstract}
SUMMARY
Evidence that the alcohol dehydrogenase enzymes in barley are specified by two genes, $A d h 1$ and $A d h 2$ whose products (ADH1 and ADH2) associate by dimerization to give three isozyme sets, Set I (ADH1 . ADH1 homodimer), Set II (ADH1 . ADH2 heterodimer) and Set III (ADH2 . ADH2 homodimer) is presented. Procedures for the induction and recovery of null activity mutants at the $A d h 1$ locus are described. One such mutant, $A d h 1-M 9$, when homozygous results in the absence of Set I and Set II isozymes and in a decrease in the rate of induction of alcohol dehydrogenase activity caused by flooding.
\end{abstract}

\section{INTRODUCTION}

AlCOHOL dehydrogenase (ADH, alcohol: $\mathrm{NAD}^{+}$oxidoreductase, E.C. 1.1.1.1.) activity has bien studied in a large number of different plant species including maize (Schwartz and Endo, 1966), wheat (Hart, 1970), sunflower (Torres, 1974), pearl-millet (Banuett-Bourrillon and Hague, 1979), tomato (Tankesley and Jones, 1981) and others (Marshall et al., 1974; Gottlieb, 1974; Roose and Gottlieb, 1980a; Roose and Gottlieb, $1980 b$ ). The ADH systems of these plants display great similarities. In all cases in which it has been investigated $\mathrm{ADH}$ appears to be a dimer. Frequently ADH isozymes specified by duplicate loci are observed. These loci often display differential expression in response to environmental or developmental stimuli (Freeling, 1973; Tankesley and Jones, 1981), suggesting that although they contain relatively similar structural components their regulatory components differ significantly.

Mutants deficient in ADH activity have been isolated by the use of chemical selective techniques in yeast (Megnet, 1967), Drosophila (Sofer and Hatkoff, 1972) and maize (Schwartz and Osterman, 1976; Cheng and Freeling, 1976; Freeling, 1977; Freeling and Cheng, 1978). A method has also been devised for the biochemical selection of haploid maize embryos utilising the ability of Adh 1 null mutant haploid embryos to survive exposure to levels of allyl alcohol which kill diploid (Adh $1+/$ Adh 1 null) embryos (Dhaliwal and King, 1979). These selective techniques involve the exposure of organisms to chemicals which kill wild-type individuals but to which the mutants, by virtue of their reduced or nill ADH activity are resistant.

This paper describes procedures for the isolation of barley Adh 1 null mutants, and the effects of one such mutation on the ADH isozyme pattern and on the rate of induction of ADH activity by root flooding. 


\section{MAterials AND METHODS}

Barley (Hordeum vulgare cv. Proctor) seed was supplied by the National Seed Development Organisation.

\section{(i) Mutagenesis and aleurone ADH stain screening}

Sodium azide mutagenesis was performed as described by Kleinhofs $e t$ al. (1978), $\mathrm{M}_{2}$ seeds are imbibed overnight at $20^{\circ} \mathrm{C}$. A thin transverse section from the distal end of each seed is immersed in a drop of $\mathrm{ADH}$ stain for 10 mins. Following this the aleurone layer is examined at $40 \times$ magnification. The aleurone layers of wild-type $(A d h 1+)$ seeds stain an intense blue-black under these conditions. Seeds whose sections contain aleurone layers with a lower than normal intensity of stain (by visual estimation) were grown to maturity. The ADH stain consists of $1 \mathrm{ml} 0.1 \mathrm{M}$

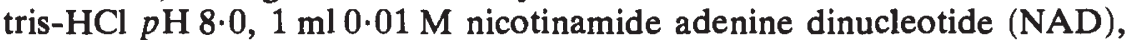
$1 \mathrm{ml} \mathrm{0.01} \mathrm{M} \mathrm{nitroblue} \mathrm{tetrazolium} \mathrm{chloride} \mathrm{(NBT),} 1 \mathrm{ml} 95$ per cent ethanol.

\section{(ii) Starch gel electrophoresis}

Starch gel electrophoresis was essentially as described by Schwartz and Endo (1966). Complete plant root systems or excised seed germinal tissues were ground up in a small quantity of pre-chilled $0.05 \mathrm{M}$ sodium phosphate,

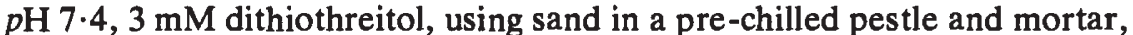
and the resulting extracts were absorbed onto filter-paper wicks (Whatman's No. 3). The gel was run at $4^{\circ} \mathrm{C}$. The $\mathrm{ADH}$ stain consisted of $100 \mathrm{ml} 0.1 \mathrm{M}$ tris- $\mathrm{HCl} p \mathrm{H} 8 \cdot 0,8 \mathrm{ml}$ ethanol (absolute), $30 \mathrm{mg} \mathrm{NAD}, 20 \mathrm{mg}$ NBT and $5 \mathrm{mg}$ phenazine methosulphate (PMS).

\section{(iii) Allyl alcohol resistance}

An aliquot of allyl alcohol was added to molten 0.75 per cent agar (Oxoid, No. 3) and the mixture immediately poured, after thorough mixing, into petri plates. $20 A d h 1-M 9$ or $50 A d h 1+$ seeds were placed on each plate. Germination was scored after $48 \mathrm{hrs}$ at $20^{\circ} \mathrm{C}$.

\section{(iv) Root flooding conditions and ADH activity assay}

$A d h 1+$ and $A d h 1-M 9$ seeds were individually planted in $9 \mathrm{~cm}$ pots in vermiculite (Vermiculite Ltd.) and placed in a controlled environment chamber at a constant temperature of $20^{\circ} \mathrm{C}$ with an $18 \mathrm{hr}$ day. They were watered with $0.5 \times$ strength Hoagland's nutrient solution. After nine days growth some of each genotype were flooded by raising the water-table to the vermiculite surface with the nutrient solution. The flooding was maintained by placing the plant pots in opaque beakers and then filling these up to the required volume. The plants were harvested after $0,2,4$ and 6 days of treatment and the $\mathrm{ADH}$ activity in their root systems visualized by starch gel electrophoresis or assayed by the following procedure. Individual complete plant root systems, after careful washing, were ground

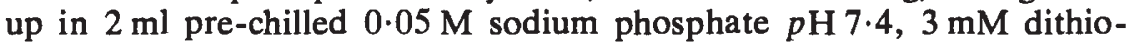
threitol, in a pre-chilled pestle and mortar with sand. The homogenate was 


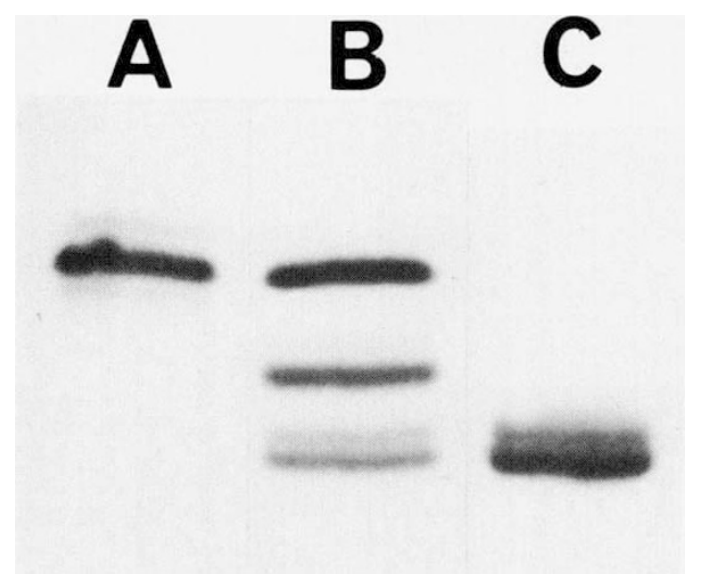

FIG. 1.-Gel demonstrating three ADH isozyme sets. Samples were run from top (sample origin) to bottom (anode). Samples: (A) germinal tissue extract from dry seed, (B) extract from 8 day old $A d h 1+$ roots flooded 4 days, (C) extract from 8 day old $A d h 1-M 9$ roots flooded 4 days. Note the existence of Set I only in A, Sets I, II and III in B, and Set III only in $\mathrm{C}$. 
centrifuged at 13,000 r.p.m. for 30 mins at $4^{\circ} \mathrm{C}$, and $\mathrm{ADH}$ activity in the supernatant estimated essentially according to the method of Bonnichsen and Brink (1955). Change in absorbance at $340 \mathrm{~nm}$, due to the reduction of NAD, was recorded over two minutes at $23^{\circ} \mathrm{C}$. The enzyme reaction mixture consisted of $2.7 \mathrm{ml} 0.1 \mathrm{M}$ glycine- $\mathrm{NaOH}, p \mathrm{H} 10 \cdot 00 ; 0.1 \mathrm{ml} 10$ per cent ethanol; $0.1 \mathrm{ml} 5 \mathrm{mg} \mathrm{ml}^{-1} \mathrm{NAD}$ and $0.1 \mathrm{ml}$ of the supernatant. In the control cuvette the ethanol was replaced by deionized $\mathrm{H}_{2} \mathrm{O}$. Two readings were taken for each root. The change in optical density with time was linear for at least one minute. The activity was calculated as the mean of the two recordings, and expressed as $\mu$ moles NAD reduced per minute per root. Recovery experiments in which lyophilized yeast ADH is added to the extraction buffer suggest that approximately 10 per cent of the total extractable ADH activity is lost during our extraction procedure (Harberd, unpublished). Hence our values of ADH activity per root are probably an underestimate of the true $\mathrm{ADH}$ content.

Tris (hydroxymethyl)-aminomethane(tris), nicotinamide adenine dinucleotide (NAD), nitroblue tetrazolium chloride (NBT), starch, dithiothreitol, phenazine methosulphate (PMS), 2,4-Dichlorophenoxyacetic acid (2,4-D) and lyophilized yeast ADH were from Sigma Chemical Company. All other chemicals were from British Drug Houses Ltd.

\section{Results}

\section{(i) Electrophoretic separation of ADH isozymes in seed and flooded root}

In the dry seed the $\mathrm{ADH}$ activity in extracts from both germinal tissue and endosperm can be resolved as a single anodally migrating band in starch gel electrophoresis (fig. 1(A)). The ADH pattern observed in extracts from flooded roots differs from that observed in dry seeds. The activity is now resolved as three anodally migrating bands one of equal and the other two of greater electrophoretic mobility when compared to the band observed in extracts from dry seeds (fig. 1(B)). These faster migrating bands also appear in extracts from the germinal tissue of immersed seeds (Harberd and Edwards, 1980).

\section{(ii) The isolation of Adh1 null mutants}

The ADH activity in dry seeds and also in aerobically germinating seeds can be resolved as a single band in starch gel electrophoresis. If this single band represents the product of a single locus a one-hit mutation resulting in its loss is feasible.

Twenty-seven low staining individuals were isolated from $6300 \mathrm{M}_{2}$ barley seeds by aleurone ADH stain screening, of which 14 survived to produce seed. Two of these 14 low staining lines were confirmed as Adh 1 null homozygous lines by electrophoretic and other modes of analysis. The mutant alleles were labelled $A d h 1-M 9$ and $A d h 1-M 11$ respectively. The Adh 1-M9 mutation has been observed to be stable and heritable over at least five generations. It behaves as a classic monofactorial recessive mutation producing the expected $3: 1$ phenotypically wild-type to mutant ratio in the progeny of selfed heterozygotes (Harberd, 1981).

Since a germinating $A d h 1-M 9$ seed should contain no $\mathrm{ADH}$ it should be relatively resistant to allyl alcohol $(\mathrm{ADH}$ converts allyl alcohol to the 
highly toxic acrylaldehyde). The results of an experiment demonstrating the effect of a range of allyl alcohol concentrations on the germination of wild-type $A d h 1+$ and $A d h 1-M 9$ seeds are presented in fig. 2. Under these conditions $A d h 1-M 9$ seeds display a greater resistance to allyl alcohol than do $A d h 1+$ seeds, and are able to germinate on agar containing concentrations of allyl alcohol lethal to normal seeds. Other experiments have shown that mutant seeds are not susceptible to the "cross-feeding" of acrylaldehyde from adjacent $A d h 1+$ seeds and that exposure of seeds to allyl alcohol does not adversely affect the future development of survivors (Harberd, 1981).

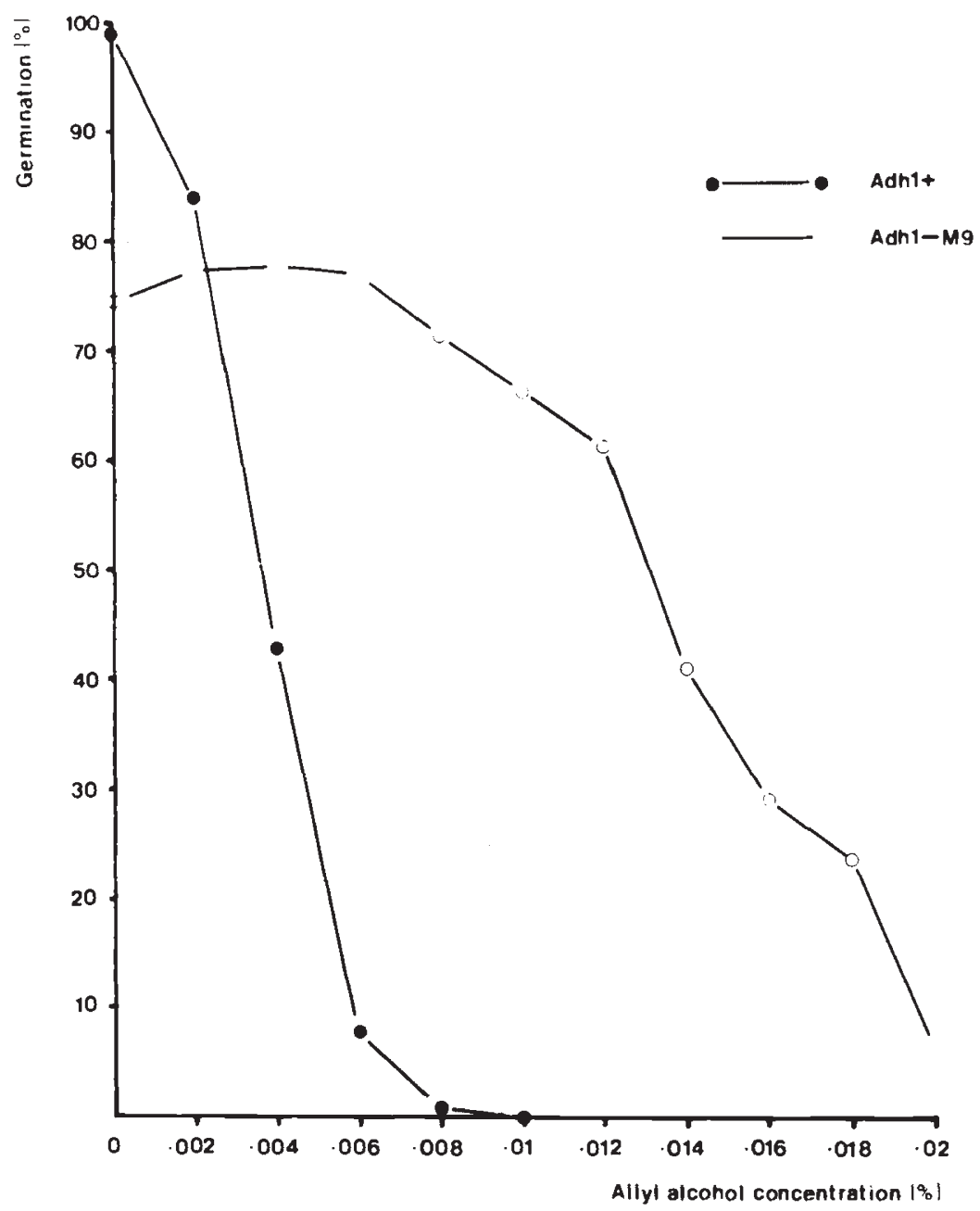

FIG. 2.-Mean germination frequencies of $A d h 1+(O)$ and $A d h 1-M 9(O)$ seeds converted to percentage germination and plotted against their respective allyl alcohol concentrations. Each point represents the mean of at least 10 plates. The highest standard error observed was 5 per cent $(A d h 1+, 0 \cdot 004$ per cent allyl alcohol). The others were substantially lower than this $(<2$ per cent). 


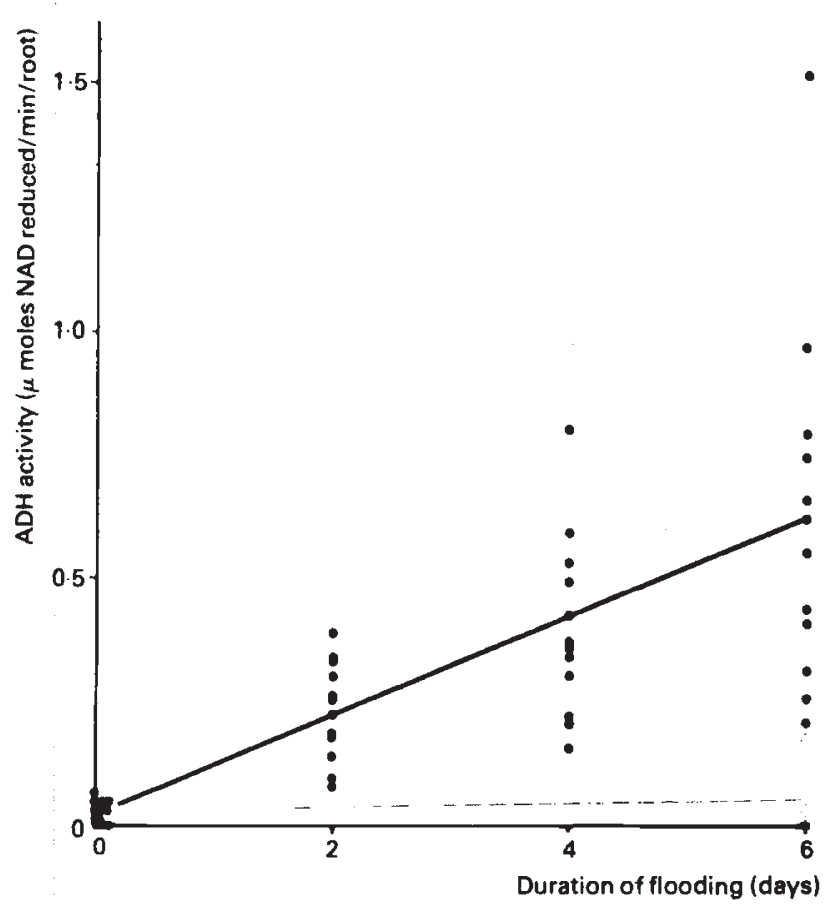

FIG. 3.-ADH activity per flooded root system is plotted against duration of flooding. Each point represents the activity in a single $A d h 1+$ flooded $(O)$ and non-flooded $(\triangle)$ root system. The solid line represents the linear induction curve calculated by regression analysis (see text). The broken line represents the relatively stable ADH levels in aerobic roots.

(iii) The effect of the Adh1-M9 mutation on the ADH isozymes

As predicted above dry seed extracts of $A d h 1-M 9$ show no $A D H$ activity in starch gel electrophoresis (data not shown). However extracts from flooded $A d h 1-M 9$ roots clearly resolve activity in a position corresponding to that of the fastest migrating band observed in extracts from flooded Adh1 + roots (fig. 1(C)).

(iv) The induction of $A D H$ activity in seedling roots by root flooding

The results of an experiment designed to investigate the effect of flooding on the induction of ADH activity in Adh 1 + roots are presented in fig. 3 . The data were subjected to conventional regression analysis, and or thogonal comparisons were employed to investigate the relative significance of the linear, quadratic and cubic relationship components in the data (Steel and Torrie, 1960). The results of a similar experiment on $A d h 1-M 9$ plants are presented in fig. 4 and were analysed in the same way.

The results indicate a linear relationship between flooding duration (up to six days) and level of induced $\mathrm{ADH}$ activity in both $A d h 1+$ and Adh 1-M9 roots. Also the rate of induction of ADH activity in Adh1-M9 roots $\left(2.55 n\right.$ moles NAD reduced $\mathrm{min}^{-1} / \mathrm{root} /$ day) is significantly less than 


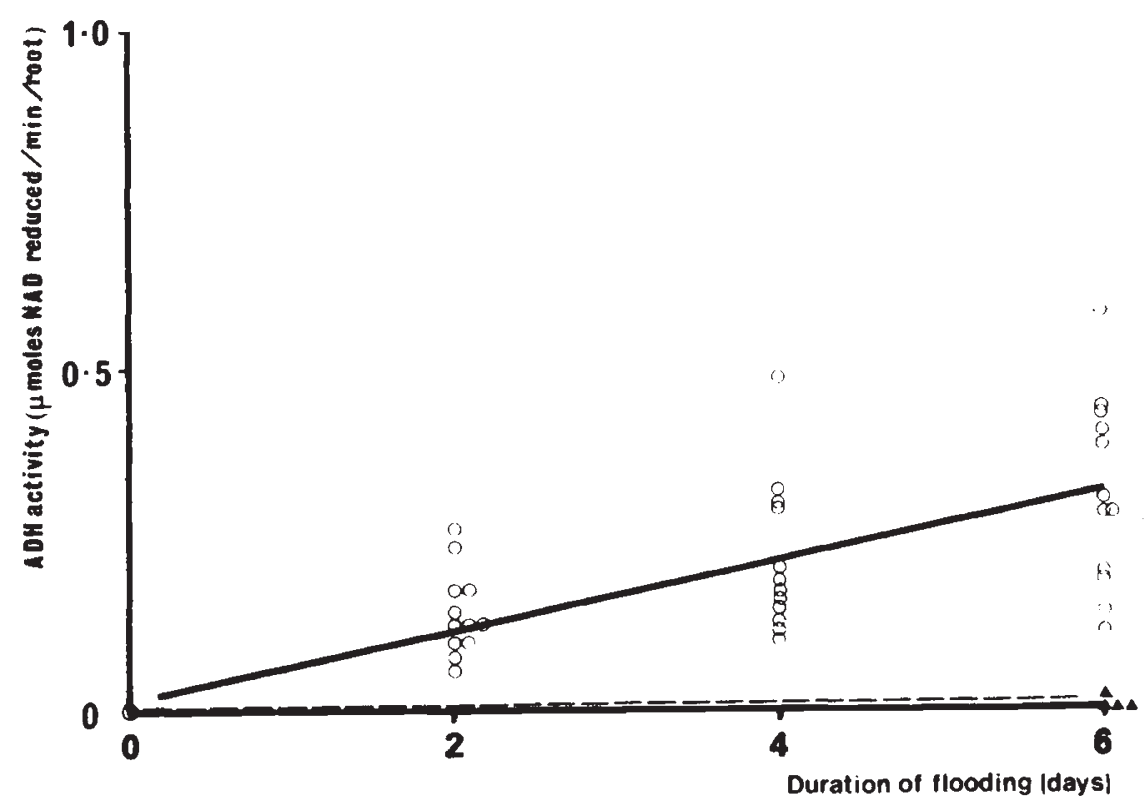

FIG. 4.-ADH activity per flooded root system plotted against duration of flooding. Each point represents the activity in a single $A d h 1-M 9$ flooded $(O)$ and non-flooded $(\boldsymbol{\Lambda})$ roots system. The solid line represents the linear induction curve calculated as described. The broken line represents the relatively stable (very low) ADH level in aerobic roots.

in $A d h 1+$ roots (4.91 $n$ moles NAD reduced $\min ^{-1} /$ root $/$ day; $t=3 \cdot 2^{* *}$; $\left.n=90, t_{0 \cdot 01}=2 \cdot 7\right)$. Hardly any activity is to be found in untreated roots of either $A d h 1+$ or $A d h 1-M 9$ plants.

\section{DisCusSION}

From the data presented we propose the following model (fig. 5). $\mathrm{ADH}$ in barley is specified by two loci, $A d h 1$ and $A d h 2$. The single ADH band found in germinal tissue and endosperm of dry seed and also in pollen (Harberd, 1981) is specified by the Adh 1 locus. This band is designated the Set I band. The appearance of the two new bands Set II and Set III can be explained by the induction by flooding of the product of another locus, Adh2. ADH is known to be a dimeric enzyme in maize (Fischer
A
B
Product Dimers
Loci

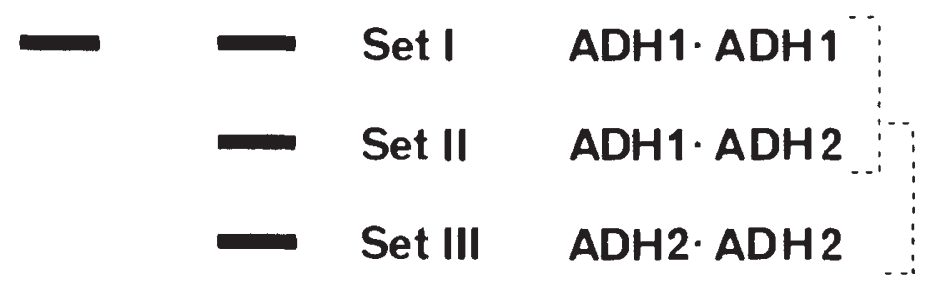

\section{Adh 1}

Adh 2

FIG. 5.-Diagram of the two-locus model for alcohol dehydrogenases in barley, analogous to that proposed for maize. 
and Schwartz, 1973), wheat (Hart, 1971) and pearl-millet (BanuettBourrillon and Hague, 1979). The existence of the Set II band can thus be explained by postulating a heterodimerization of the ADH1 and ADH2 polypeptides. The data support this model. When the Adh1-M9 mutant root system is flooded only the Set III band is observed. The conclusion is that both the Set I and Set II bands are affected by a lesion at a single locus, a specific prediction of the model.

Adh 1-M9 mutants are comparatively resistant to allyl alcohol, and as a result allyl alcohol can be employed as a selective agent for further $A d h 1$ null mutants. The isolation of such mutants is currently in progress in this laboratory. $\mathrm{M}_{2}$ seeds (resulting from mutagenic treatment with sodium azide or $\gamma$-irradiation) are germinated on agar containing allyl alcohol. Those achieving germination are further screened by testing electrophoretically a small portion of distal endosperm for absence of ADH1 activity. Seedlings passing both tests are grown to maturity. Unfortunately $A d h 2$ null mutations will probably not be recovered using these procedures since the $A d h 2$ locus is not expressed in aerobically germinating seeds.

ADH activity is induced in $A d h 1+$ barley seedling roots by immersion. Sets I, II and III are induced, non-immersed roots having only trace ADH activity. A linear relationship between induced $\mathrm{ADH}$ activity level and duration of flooding is observed in roots of both Adh $1+$ and Adh 1-M9 plants, and $A d h 1-M 9$ plant roots display a significantly lower rate of induction than $A d h 1+$ plant roots. The fact that these zero order linear induction curves are observed in both genotypes suggests that each isozyme set is accumulating linearly with time (the activity in $A d h 1-M 9$ roots being contributed entirely by the Set III isozyme).

It should be pointed out that our use of the term induction to describe the observed increase in ADH activity does not imply any one particular mechanism for that increase. We have, for example, done no experiments to determine if the observed increase in activity is correlated with de novo $\mathrm{ADH}$ protein synthesis. In maize, anaerobic treatment of root tissue results in the cessation of general (aerobic) protein synthesis together with initiation of synthesis of a few polypeptides designated anaerobic polypeptides. Amongst these anaerobic polypeptides is ADH (Sachs and Freeling, 1978; Sachs et al., 1980). It seems likely that the case for barley will turn out to be similar.

Hence the barley ADH enzymes, like those of maize, are specified by two loci, $A d h 1$ and $A d h 2$. However there are clear differences between the two systems. In maize the $\mathrm{ADH} 2$ polypeptide appears to have a much lower specific activity than the ADH1 polypeptide (Freeling, 1973). The barley $\mathrm{ADH} 1$ and $\mathrm{ADH} 2$ polypeptides would not seem to differ in their activities to such an extent. Also $A d h 1$ and $A d h 2$ in maize are unlinked, Adh 1 being located on the long arm of chromosome 1 (Freeling and Birchler, 1981) and $A d h 2$ on the short arm of chromosome 4 (Freeling and Dloughy, unpublished, referenced in Freeling and Birchler, 1981) whereas $A d h 1$ and $A d h 2$ in barley are apparently tightly linked (at least in Hordeum spontaneum, Brown, 1980) and located on chromosome 4 (Islam et al., 1981). It is tempting to suggest that the unlinked maize $A d h 1$ and $A d h 2$ genes represent an evolutionary divergence from the tightly linked $A d h 1$ and $A d h 2$ genes found in barley. The apparent relative conservancy of the $A d h 1$ and $A d h 2$ coding sequences is in marked contrast 
to the more dynamic changes which have occurred during evolution in the positional arrangement of these loci with respect to one another.

Acknowledgements.-N.P.H. acknowledges receipt of a Science Research Council CASE award. Thanks are due to Dr J. A. Barrett for advice on statistical analysis and to Prof M. Freeling and Dr T. ap Rees for constructive criticism.

\section{REFERENCES}

BANUETT-BOURRILlon, F., AND HAGUE, D, K. 1979. Genetic analysis of alcohol de. hydrogenase isozymes in Pearl Millet (Pennisetum typhoides). Biochem. Genet., 17, 537-552.

BONNICHSEN, R, K., AND BRINK, N. G. 1955. Liver alcohol dehydrogenase. In Colowick, S. P., and Kaplan, N. O. (eds.) Methods in Enzymology, vol. 1, Academic Press, New York, pp. 495-500.

BROWN, A. H. D. 1980. Genetic basis of the alcohol dehydrogenase polymorphism in Hordeum spontaneum. J. Hered., 70, 127-128.

CHENG, D. S. K., AND FREELING, M. 1976. Methods of maize pollen in vitro germination, collection, storage, treatment with toxic chemicals and recovery of resistant mutants. Maize Genetics Cooperation News Letter, 50, 11-13.

DHALIWAL, H. S., AND KING, P. J. 1979. Biochemical selection of immature, haploid embryos of Zea mays L. Theoret. Appl. Genet., 55, 257-262.

FISCHER, M., AND SCHWARTZ, D. 1973. Dissociation and reassociation of maize ADH: allelic differences in requirement for zinc. Molec. gen. Genet., 127, 33-38.

FREELING, M. 1973. Simultaneous induction by anaerobiosis or 2,4-D of multiple enzymes specified by two unlinked genes: differential $A d h 1-A d h 2$ expression in maize. Molec. gen. Genet., 127, 215-227.

FREELING, M. 1977. Spontaneous forward mutation versus reversion frequencies for maize Adh 1 in pollen. Nature, 267, 154-156.

FREELING, M., AND BIRCHLER, J. A. 1981. Mutants and variants of the alcohol dehydrogenase-1 gene in maize. In Setlow, J. W., and Hollaender, A. (eds.) Genetic Engineering: Principles and Methods, vol. 3, Plenum Press, New York (in press).

FREELING, M., AND CHENG, D. S. K. 1978. Radiation-induced alcohol dehydrogenase mutants in maize following allyl alcohol selection of pollen. Genetical Research, 31, 107-129.

GOTTLIEB, L. D. 1974. Genetic duplication and fixed heterozygosity for ADH in the diploid plant Clarkia franciscana. Proc. Natl. Acad. Sci. U.S.A., 71, 1816-1818.

HARBERD, N. P. 1981. A Genetical Investigation of the Alcohol Dehydrogenase System in Barley. Ph.D. Thesis, Univ. Cambridge.

HARBERD, N. P., AND EDWARDS, K. J. R. 1980. Evidence that two loci, Adh1 and Adh 2, code for alcohol dehydrogenase, the second being inducible by anaerobiosis. Barley Genetics Newsletter, 10, 26-30.

HART, G. E. 1970. Evidence for triplicate genes for alcohol dehydrogenase in hexaploid wheat. Proc. Natl. Acad. Sci. U.S.A., 66, 1136-1141.

HART, G. E. 1971. Alcohol dehydrogenase isozymes of Triticum : dissociation and recombination of subunits. Molec. gen. Genet., 111, 61-65.

ISLAM, A. K. M. R., SHEPHERD, K. W., AND SPARROW, D. H. B. 1981. Isolation and characterization of euplasmic wheat-barley chromosome addition lines. Heredity, 46, 161-174.

KLEINHOFS, A., WARNER, R. L., MUEHLBAUER, F. J., AND NILAN, R. A. 1978. Induction and selection of specific gene mutations in Hordeum and Pisum. Mut. Res., 51, 29-35.

MARShALL, D. R., BROUE, P., AND ORAM, R. N. 1974. Genetic control of alcohol dehydrogenase isozymes in narrow-leafed lupins. J. Hered., 65, 198-203.

MEGNET, R. 1967. Mutants partially deficient in alcohol dehydrogenases in Schizosaccharomyces pombe. Arch. Biochem. Biophys., 121, 194-201.

ROOSE, M. L., AND GOTTLIEB, L. D. $1980 \mathrm{a}$. Alcohol dehydrogenase in the diploid plant Stephanomeria exigua (Compositae): gene duplication, mode of inheritance and linkage. Genetics, 95, 171-186.

ROOSE, M. L.. AND GOTTlieb, L. D. 1980b. Biochemical properties and level of expression of alcohol dehydrogenases in the allotetraploid plant Tragopogon miscellus and its diploid progenitors. Biochem. Genet., 18, 1065-1085. 
SACHS, M. M., AND FREELING, M. 1978. Selective synthesis of alcohol dehydrogenase during anaerobic treatment of maize. Molec. gen. Genet., 161, 111-115.

SACHS, M. M., FREELING, M., AND OKIMOTO, R. 1980. The anaerobic proteins of maize. Cell, 20, 761-767.

SCHWARTZ, D., AND ENDO, T. 1966. Alcohol dehydrogenase polymorphism in maize-simple and compound loci. Genetics, 53, 709-715.

SCHWARTZ, D., AND OSTERMAN, J. 1976. A polłen selection system for alcohol dehydrogenase negative mutants in plants. Genetics, 83, 63-65.

SOFER, W. H., AND HATKOFF. M. A. 1972. Chemical selection of alcohol dehydrogenase negative mutants in Drosophila. Genetics, 72, 545-549.

STEEL, R. G. D., AND TORRIE, J. H. 1960. Principles and procedures of statistics. McGraw-Hill, New York.

TANKSLEY, S. D., AND JONES, R. A. 1981. Effects of $\mathrm{O}_{2}$ stress on tomato alcohol dehydrogenase activity: description of a second ADH coding gene. Biochem. Genet., 19, $397-409$.

TORRES, A. M. 1974. Sunflower alcohol dehydrogenase: ADH1 genetics and dissociationrecombination. Biochem. Genet., 11, 17-24. 